\title{
Advances in the Testing of the Hydro-mechanical Behaviour of Shales
}

\author{
Alessio Ferrari and Lyesse Laloui \\ Swiss Federal Institute of Technology, Lausanne, EPFL, Switzerland \\ \{alessio.ferrari, lyesse.laloui\}@epfl.ch
}

\begin{abstract}
The paper presents some of the advanced experimental techniques and apparatuses that have been developed by the authors for testing the hydromechanical behaviour of shales. A methodology established for the analysis of the water retention behaviour in non-isochoric conditions is introduced; the method allows for the determination of the main drying and wetting paths in addition to the volume change response upon total suction variations. A high-pressure oedometric cell is then presented; the apparatus allows for the analysis of the transition from the pre-yield behaviour to the normally consolidated state. The analysis of the settlement versus time curves yields information on the permeability of the material as a function of the void ratio. The test results are illustrated for two Mesozoic shales from the northern region of Switzerland, namely, the Opalinus Clay from Mont Terri and the so called "Brown Dogger" from the Schlattingen site in the Molasse Basin.
\end{abstract}

\section{Introduction}

The geomechanical behaviour of shales is quickly becoming one of the most important issues in modern geomechanics, largely driven by the nuclear waste geological storage and petroleum industries (i.e., the extraction of gas shale and the sequestration of $\mathrm{CO}_{2}$ ). In any such application, a deep understanding of the hydromechanical behaviour of the involved materials is of primary significance. The water retention mechanisms play a major role in either fluid trapping due to the capillary forces present in low permeability formations or in the resaturation of shale formations after ventilation, as in the case of deep geological repositories. The swelling/shrinkage of shale is related to suction, or the degree of saturation variations. The mechanical properties and the permeability are of primary importance in determining the production capacity of gas shale reservoirs. In reference to the mentioned issues, this paper presents the advanced experimental techniques and apparatuses that have been recently developed by the authors for testing the hydro-mechanical behaviour of shales. A methodology for obtaining the water retention properties of shales is presented first. A high-pressure oedometric apparatus is then introduced. Selected test results are presented for two shales from the northern region of Switzerland. 


\section{Tested Shales}

Test results are presented for two shales from the northern region of Switzerland: the Opalinus Clay sample was obtained from the Mont Terri Underground Laboratory and the "Brown Dogger", from a deep geothermal well (depth of 766.67 and $778.30 \mathrm{~m}$ ) near the village of Schlattingen in the Molasse Basin. The tested Opalinus Clay (OPA) was recovered in the Gallery 98 of the Mont Terri URL from the shaly facies, consisting of dark grey silty, calcarerous shales with a typical clay content of 55-60\%, 25-30\% carbonate, 5-10\% quartz and 10-15\% biodetritus. The core samples of "Brown Dogger" (BD) originated from the Varians- and Parkinsoni-Würtembergica beds (Bathonian/Bajocian age), consisting of silty to clay-rich marls with a clay content of $25-45 \%, 30-50 \%$ carbonate and 20$25 \%$ quartz.

The results of the geotechnical identification of the cores are reported in Table 1 , which presents the particle density $\left(\rho_{s}\right)$, the bulk density $(\rho)$, the water content $(w)$, the void ratio $(e)$, the degree of saturation $\left(S_{r}\right)$ and the Atterberg limits (the liquid limit $w_{L}$ and the plastic limit $w_{P}$ ). The grain size distributions reported in Figure 1.a were obtained by sedimentation analysis. The material was first crushed using a grinder, and the fraction passing the ASTM No. 35 sieve (with an aperture diameter $d=500 \mu \mathrm{m}$ ) was selected. The crushed material was placed in distilled water along with a dispersing agent and was then shaken overnight. As seen in the figure, the obtained curves are situated on the left side of the maximum dimension of the selected material; this observation confirms that the material did not present particles with a diameter larger than the maximum dimension of the crushed blocks, and it validates the selected procedure for preparation of the sedimentation analysis. The OPA and the BD core samples were classified as CM (sandy clay) and CL-ML (silty clay with sand), respectively.

Synthetic waters aiming to reproduce the in-situ pore water composition were used throughout the tests (Pearson 1998; Mäder 2011). The osmotic suctions of the synthetic waters used were measured by a dew-point psychrometer and resulted in values of $0.9 \mathrm{MPa}$ for the BD and 1.2 MPa for the OPA.

Mercury Intrusion Porosimetry (MIP) was used to determine the pore size density function of the selected cores. The MIP technique includes the forced penetration of mercury into a sample and the measurement of the intruded volume of mercury as a function of the applied pressure. The required pressure is inversely proportional to the size of the progressively filled pores.

Table 1 Geotechnical characterization of the tested shales.

\begin{tabular}{lccccccc}
\hline Shale & $\begin{array}{c}\rho_{s} \\
\left(\mathrm{Mg} / \mathrm{m}^{3}\right)\end{array}$ & $\begin{array}{c}\rho \\
\left(\mathrm{Mg} / \mathrm{m}^{3}\right)\end{array}$ & $\begin{array}{c}w \\
(\%)\end{array}$ & $\begin{array}{c}e \\
(-)\end{array}$ & $\begin{array}{c}S_{r} \\
(\%)\end{array}$ & $\begin{array}{c}w_{L} \\
(\%)\end{array}$ & $\begin{array}{c}w_{P} \\
(\%)\end{array}$ \\
\hline OPA & 2.74 & 2.46 & 6.9 & 0.21 & 92 & 38 & 23 \\
\hline BD & 2.72 & 2.55 & $2.7-3.5$ & $0.09-0.11$ & $78-92$ & $25-29$ & 23 \\
\hline
\end{tabular}


To minimise the effects of shrinkage during drying, the MIP tests were carried out on freeze-dried samples, which was achieved by sublimation inside a vacuum chamber at 0 mbar and $-50^{\circ} \mathrm{C}$ for 24 hours. The tests were carried out using a Thermo Electron Corporation MIP apparatus composed of two operating units: a low pressure (max. pressure $100 \mathrm{kPa}$ ) and a high pressure (max. pressure 400 $\mathrm{MPa}$ ) unit. The results of the MIP tests are depicted in Figure 1.b in terms of the pore size density function (PSD), which is the derivative of the cumulated intruded void ratio with respect to the logarithm of the entrance pore diameter.

The total cumulated void ratios obtained with the MIP tests were 0.13 and 0.074 for the OPA and the BD sample, respectively. A comparison of the void ratio values reported in Table 1 demonstrates that not the overall porosity was intruded and therefore investigated with the MIP tests; this limit can be related to pores on the surface of the samples that were filled with mercury before the pressure increments started and to the smallest pores that required higher pressures to be intruded (minimum pore diameter that could be intruded with the used apparatus was $3.8 \mathrm{~nm}$ ). The PSD functions were found to be unimodal for both tested shales, showing pore modes at approximately $20 \mathrm{~nm}$ and $15 \mathrm{~nm}$ for the OPA and the BD samples, respectively.
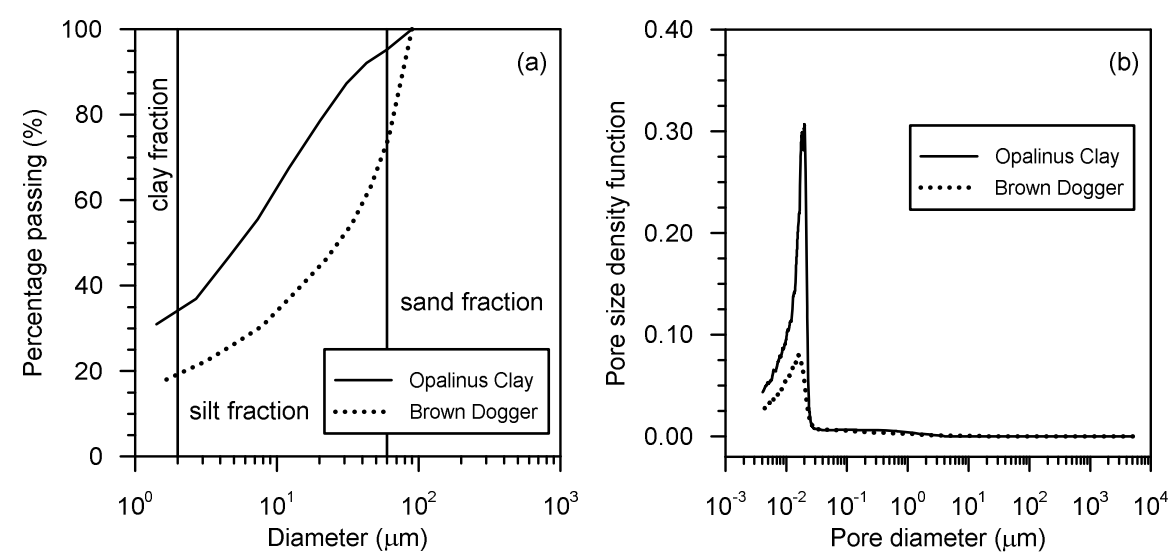

Fig. 1 Grain size distribution (a) and pore size density function (b) of the tested shales.

\section{Water Retention Behaviour}

The strength and stiffness of shales are significantly influenced by the degree of saturation or alternatively by the suction (among others, see: Valès et al. 2004; Ramos da Silva et al. 2008). Changes in the degree of saturation are common in several engineering applications, including the drying and re-imbibition of host rock formations for waste repositories and the two-phase flow in shale gas 
reservoirs. Despite the recognised impact of suction on shale behaviour, few experimental tests have been carried out to evaluate the water retention properties of shales (e.g., Ramos da Silva et al. 2008; Muñoz 2007; Zhang et al. 2007).

This section describes the experimental methodology established to analyse the water retention behaviour of shales under unstressed conditions. The methodology involves the direct control of the shale water content and the subsequent measurement of the suction at equilibrium by a psychrometer. To compute the degree of saturation, the volume is measured for each equilibrated state.

The imposed water content is applied differently for the wetting and drying paths. Slices measuring $7-8 \mathrm{~mm}$ in height are initially obtained from the shale core. To obtain the main drying paths, the core slices are initially wetted by placing them in a sealed-glass jar on filter papers, which in turn are placed on a porous stone filled by synthetic water (corresponding to the in situ water composition). At this stage, the slices are wetted by capillary action, allowing for volume changes. The weight evolution over time is measured to assess the equilibration. Nearly two weeks are required for the slices to equalise. The wetted slices are then divided in small parts measuring approximately $20 \times 20 \times 8 \mathrm{~mm}^{3}$. Each part is placed in a desiccator and dried for the amount of time necessary to achieve the desired water content of that particular part. After the drying step, the parts are packed for at least three days to allow for the internal redistribution of water. When the main wetting paths are sought, the core slices are initially placed in a desiccator containing silica gel and left to dry for approximately three weeks (applied total suction of approximately $270 \mathrm{MPa}$ ) until no significant change in their weight can be detected. The slices are then cut in pieces and a certain amount of synthetic water is added to each part to obtain the target water content. Each part is placed in a hermetic container for one week to allow for the internal redistribution of water. The total suction of each specimen is measured using a WP4c dewpoint psychrometer (Leong et al. 2003; Cardoso et al. 2007). The psychrometer used gives indirect measures of the total suction of a sample by reading the relative humidity established by the sample in a closed environment. The chilled-mirror dew point technique is used to measure the relative humidity. The total suction is then obtained by the psychrometric law (Thomson, 1871) which relates the relative humidity $(R H)$ and the absolute temperature $(T)$ to the total suction $(\psi)$ :

$$
\psi=-\frac{\rho_{w} R T}{M_{w}} \ln (R H),
$$

where $R$ is the universal gas constant and $\rho_{w}$ and $M_{w}$ are the density and the molecular mass of water, respectively.

A fluid displacement technique is used to measure the volume of each tested specimen after equalisation. The technique uses pycnometers filled with kerdane, which is used for its immiscibility with water and its ability to invade the air-filled pore spaces in the surface without affecting the soil structure (Peron et al. 2007). 
The water retention behaviour of the OPA and the BD core samples are reported in Figures 2 and 3, respectively. The results are depicted in terms of the water content, the void ratio and the degree of saturation versus the total suction. Each point represents a measurement average of three specimens, each of which followed an identical drying/wetting path. The initial state of each sample is also depicted. Both materials had an initial degree of saturation close to one, which is in agreement with the fact that both materials were reported to be saturated in situ. The initial state was found for both materials along the main drying paths as a consequence of the coring process and the exposure to atmosphere before preservation.
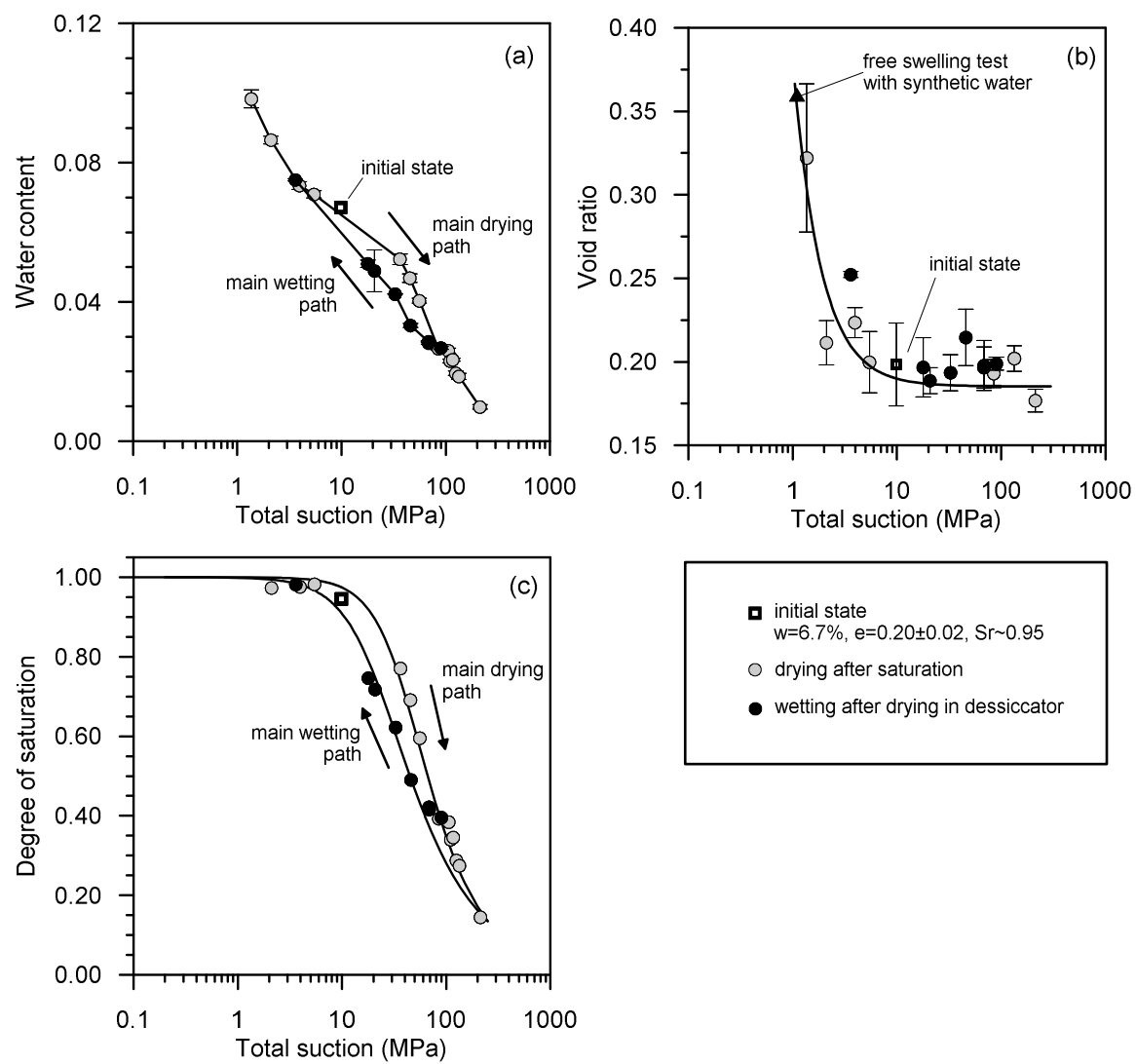

口 initial state

$w=6.7 \%, e=0.20 \pm 0.02, \mathrm{Sr} \sim 0.95$

drying after saturation

- wetting after drying in dessiccator

Fig. 2 Water retention behaviour of the Opalinus Clay core sample: the water content (a), the void ratio (b) and the degree of saturation (c) as a function of the total suction. 

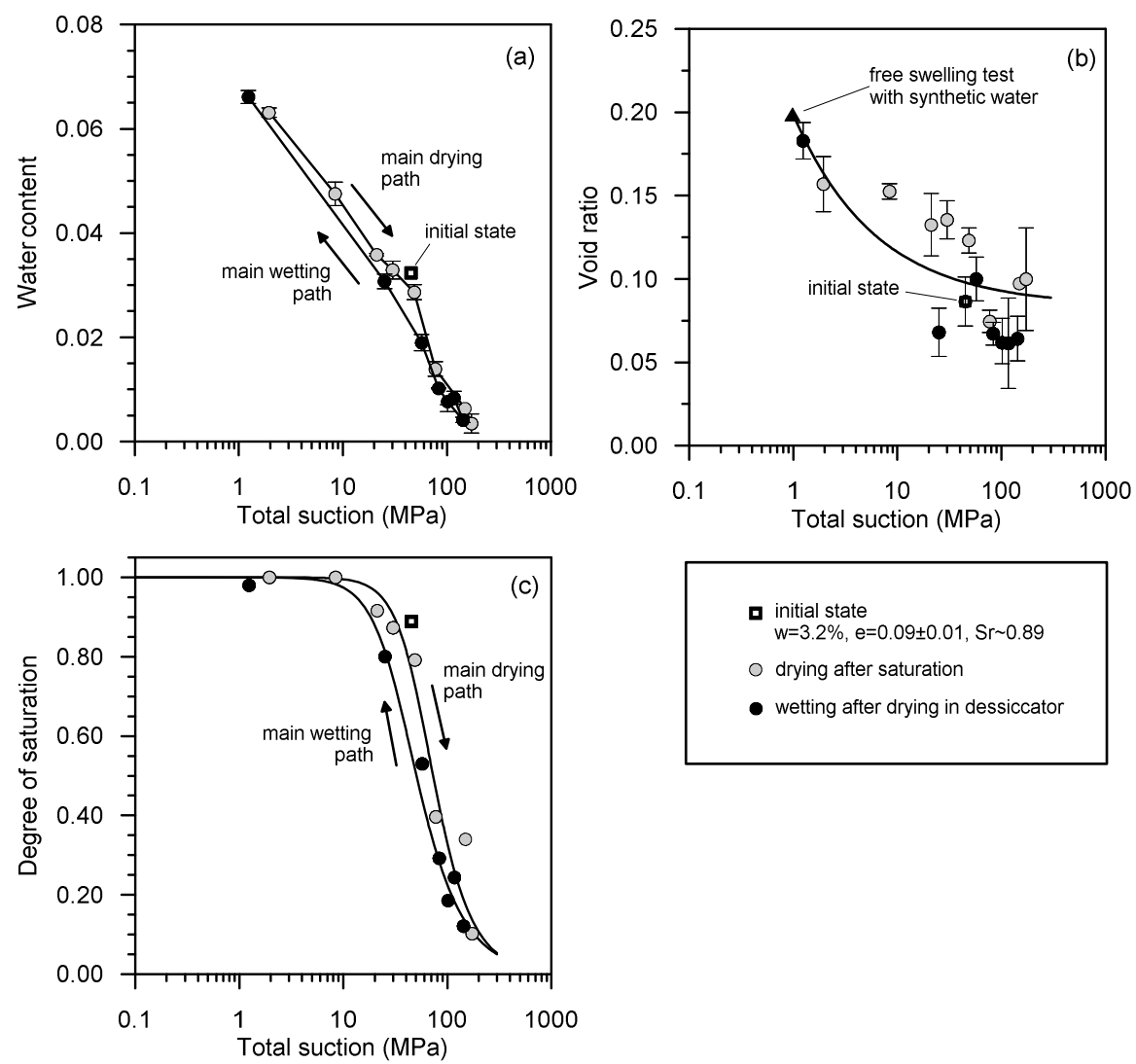

Fig. 3 Water retention behaviour of the Brown Dogger core sample: the water content (a), the void ratio (b) and the degree of saturation as a function of the total suction.

The main drying and wetting paths are well distinguished, and hysteresis zones can be observed. The evolution of the void ratios with the total suction (Figures 2.a and 2.b) showed that the porosity changes are more significant for the lowest range suction variations. The void ratios of the lowest measured suctions were in very good agreement with the results of the free swelling tests carried out with the same synthetic waters used for determining the water retention curves. The shrinkage limits (assumed to be defined by $\Delta \mathrm{e} / \Delta \psi<0.1 \%$ ) were identified at suction values of approximately $10 \mathrm{MPa}$ for the OPA and $15 \mathrm{MPa}$ for the BD. The corresponding water content values read along the main drying paths were $6.4 \%$ and $4.0 \%$ for the OPA and the BD, respectively. The data were fitted with the following incremental expression: 


$$
\dot{e}=-\frac{\dot{\psi}}{K_{r e f}}\left(\frac{\psi_{r e f}}{\psi}\right)^{m}\left(1+e_{0}\right) \text {, }
$$

in which $K_{\text {ref }}, \psi_{\text {ref }}$ and $m$ are the fitting parameters. The obtained values of the parameters are reported in Table 2. The retention curves, in terms of the degree of saturation, are depicted in Figures 2.c and 3.c. The experimental points were fitted using a van Genuchten's expression (1980):

$$
S_{r}=\left(1+\left(\frac{\psi}{P}\right)^{n}\right)^{\left(\frac{1}{n}-1\right)},
$$

where $P$ and $n$ are the fitting parameters; the obtained values are reported in Table 2 . The curves show an air entry value (gas entry pressure) of approximately 13 $\mathrm{MPa}$ for the OPA core sample and $22 \mathrm{MPa}$ for the BD core sample (the values computed for a degree of saturation of $95 \%$ ). The higher air entry value of the BD core sample is in agreement with the lower porosity (Table 1).

Table 2 The fitting parameters for the water retention behaviour.

\begin{tabular}{lccccccc}
\hline Shale & $K_{\text {ref }}$ & $\psi_{\text {ref }}$ & $m$ & \multicolumn{2}{c}{$n(-)$} & \multicolumn{2}{c}{$P(\mathrm{MPa})$} \\
& $(\mathrm{MPa})$ & $(\mathrm{MPa})$ & $(-)$ & wetting & drying & wetting & drying \\
\hline OPA & 14.6 & 1.32 & 2.63 & 1.82 & 2.1 & 22.0 & 41.0 \\
\hline BD & 22.0 & 0.98 & 1.55 & 2.4 & 2.8 & 35.9 & 57.2 \\
\hline
\end{tabular}

\section{High-Pressure Oedometric Tests}

A multi-purpose oedometric cell was developed to analyse the hydro-mechanical behaviour of the geomaterials at high confining stresses. The device allows for the performance of tests in non-isothermal and controlled suction conditions. This section focuses on the use of the device for testing the volume change behaviour of shales in saturated conditions. The layout of the apparatus used is depicted in Figure 4.

The cell is designed to hold cylindrical samples $(12.5 \mathrm{~mm}$ in height and $35 \mathrm{~mm}$ in diameter). The oedometer cell is inserted into a rigid stainless steel frame. The loading ram is positioned in the lower part of the system to prevent the specimen from being loaded before the test starts. The vertical load is applied by a hydraulic jack connected to a volume/pressure controller. The relationship between the controller pressure and the vertical stress on the specimen was assessed through a calibration step, which took into account the friction developed within the system (Salager et al. 2010). The maximum vertical stress that can be imposed on the 
specimen is $100 \mathrm{MPa}$. The volumetric strains are measured by three LVDTs (with a resolution of $1 \mu \mathrm{m}$ ), which are fixed to the frame and are in contact with the loading ram. The tests can be performed in incremental loads, in a constant loading rate mode or in a constant vertical strain rate mode. Two pore water pressure controllers are used to control the pore water pressure at the bottom and top basis and to measure the volume changes of the pore water.

The following procedure was developed and systematically applied to obtain the specimens for the oedometric tests. A slice with a thickness of approximately $20 \mathrm{~mm}$ was sawed without unpacking the core to minimise the sample disturbance. The diameter of the slice was then progressively reduced to obtain a disk with a diameter slightly larger than the final confining ring. The final re-coring step was performed with a hydraulic press. Finally, the lower and upper faces were smoothed using sand paper to obtain parallel and planar surfaces.

The results are presented for the tests performed by incremental loading, which attained a maximum vertical stress equal to $30 \mathrm{MPa}$ and $100 \mathrm{MPa}$ for the OPA and the BD, respectively. The high level of applied vertical stress was required to observe the transition from the over- to the normally consolidated state of each material. The specimens were initially saturated in isochoric conditions by applying a back pressure in the range of $20-50 \mathrm{kPa}$, and the developed swelling pressure was measured. Afterward, two loading-unloading cycles were performed in stages, allowing for the complete dissipation of the excess pore water pressure (drained conditions).

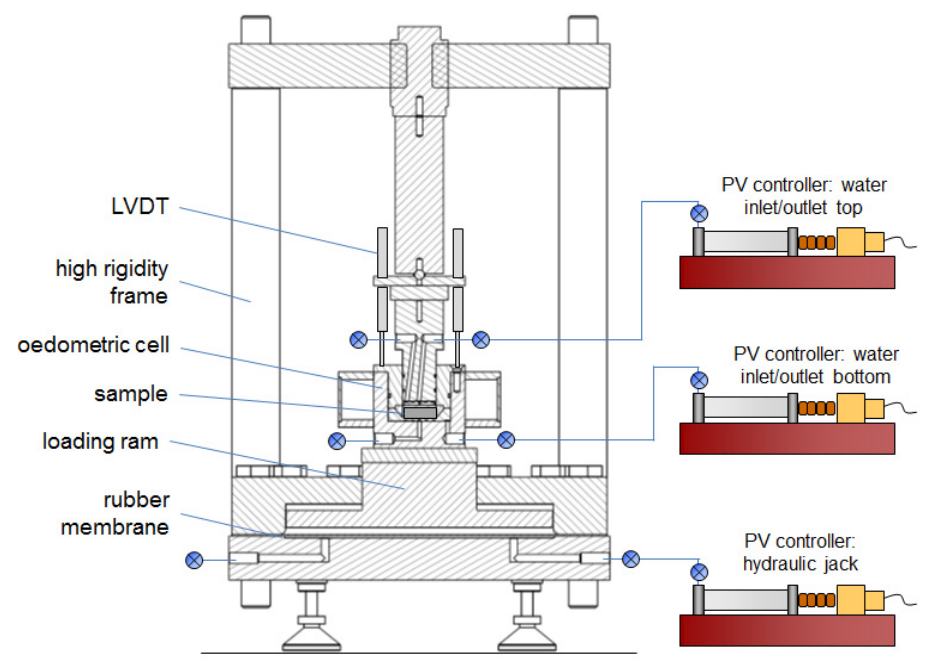

Fig. 4 A diagram of the high-pressure oedometric cell used to perform the tests in saturated conditions. 
To analyse the settlement versus time curve for each loading increment, an analytical solution was developed that considers the time requested by the controller for applying the target pressure, the deformation of the apparatus, the primary consolidation settlement for a non-instantaneous loading and the secondary consolidation (Manca et al. 2012). Figures 5 and 6 report the total settlements of the OPA and the BD, respectively, which are measured at the end of each loading step and corrected in light of the deformation of the apparatus, in terms of the volumetric strain versus the vertical effective stress. The figures also depict the volumetric strain relative to the end of the primary consolidation. The difference between the total and the end-of-primary strains is associated with the secondary consolidation component. The average computed coefficients of secondary compression were 0.0006 for the OPA and 0.0004 for the BD. The end-of-primary strains are used to compute the compression and the swelling indexes and to assess the vertical effective yield stresses (Figures 5 and 6$)$. The oedometric modulus $\left(E_{\text {oed }}\right)$ and the coefficient of consolidation $\left(c_{v}\right)$ as a function of the applied vertical effective stress are depicted in Figure 7. A systematic higher rigidity of the BD versus that of the OPA was registered; this observation was consistent with a lower initial void ratio (Table 1).

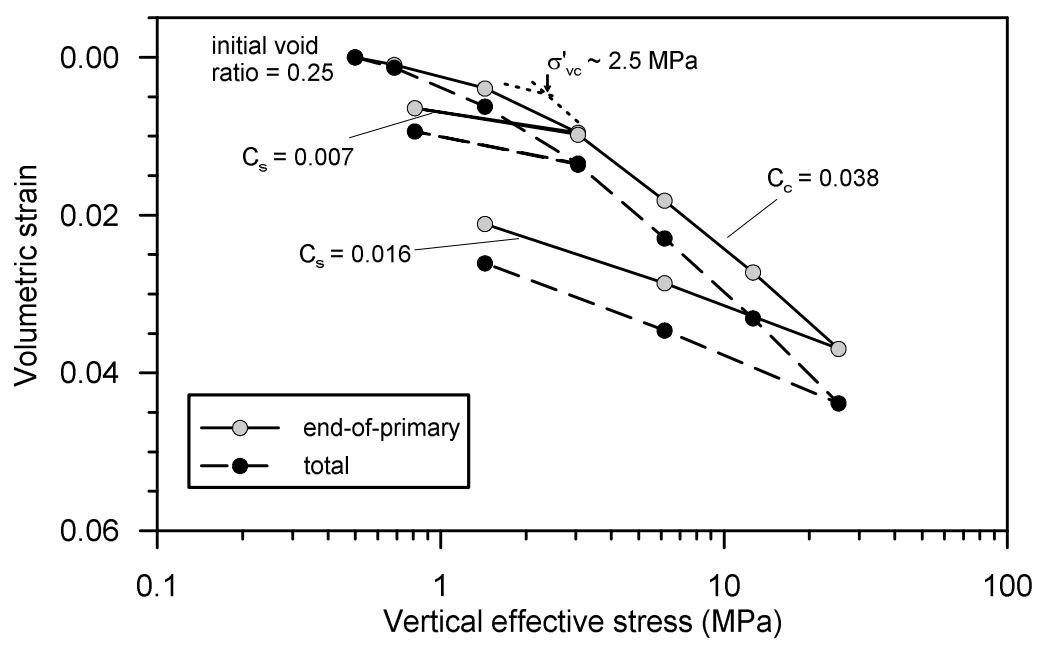

Fig. 5 Results of the oedometric test on the Opalinus Clay: the volumetric strain computed in light of the total settlement and the end-of-primary consolidation settlement 


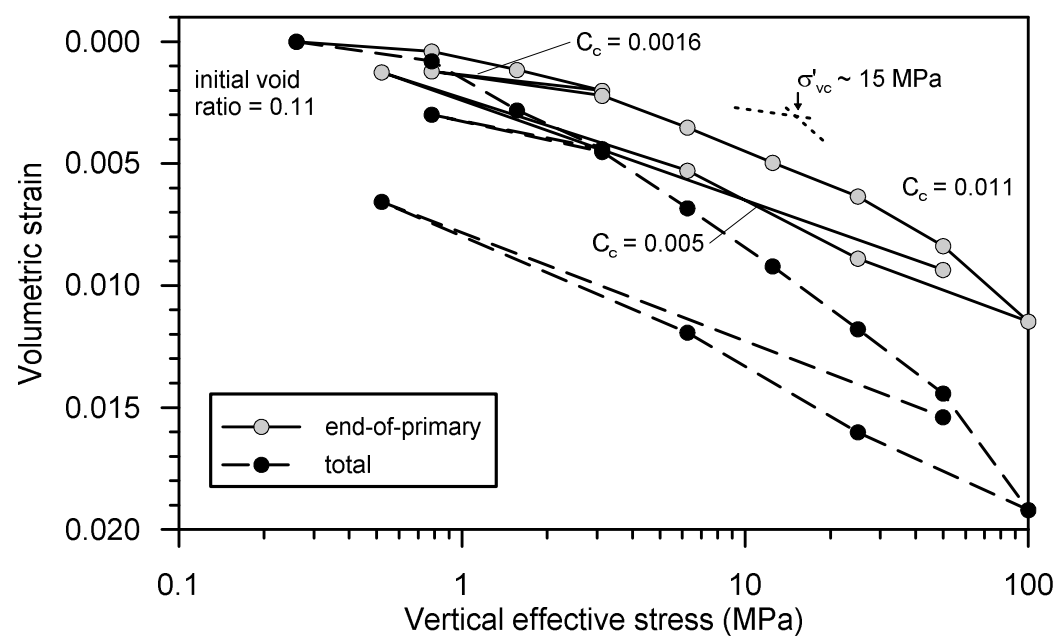

Fig. 6 Results of the oedometric test on the Brown Dogger: the volumetric strain computed in light of the total settlement and the end-of-primary consolidation settlement
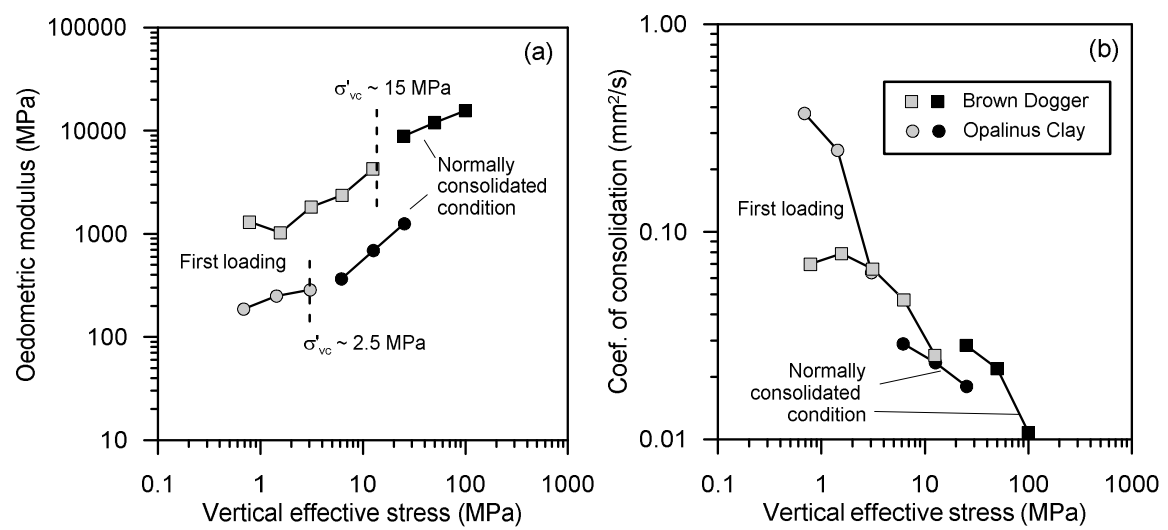

Fig. 7 The oedometric modulus (a) and the coefficient of consolidation (b), each as a function of the vertical effective stress computed from the analysis of the settlement versus time curves.

Finally, the coefficient of permeability $(K)$ was back-calculated for each load increment using the definition of the coefficient of consolidation:

$$
K=\frac{c_{v} \gamma_{w}}{E_{\text {oed }}}
$$

where $\gamma_{w}$ is the specific weight of water. The computed values for both materials are reported in Figure 8 as a function of the void ratio. The obtained trends are in very good agreement with the results of constant head permeability tests that have 
been reported by other authors (Horseman et al. 2007; Romero et al. 2012). This agreement shows that, when the end-of-primary consolidation and the coefficient of consolidation are properly computed, high-pressure oedometric tests can be used to gather information on the permeability of the tested shales within a significant range of porosity.

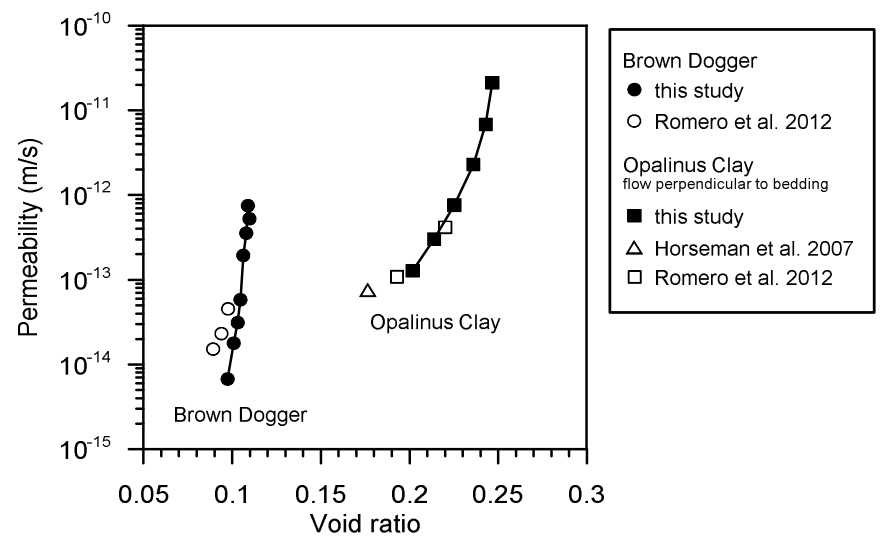

Fig. 8 The coefficient of permeability as a function of the void ratio computed from the analysis of the settlement versus time curves and compared with other available data.

\section{Closing Remarks}

The paper presents experimental techniques that have been developed for analysis of the water retention behaviour and the volumetric response of shales at high confining stress levels. Selected experimental results for two shales from the northern region of Switzerland are presented and discussed.

The low porosity of the tested shales (with principal pore modes in the range of $15-20 \mathrm{~nm}$ ) required the consideration of a wide range of suction to observe the significant variations in the degree of saturation. The procedure adopted for the analyses of the water retention behaviour of shales consisted of controlling the water content by the addition of synthetic water or by the dehydration of the material in a desiccator; additionally, the procedure involved the measurement of total suction by a dew-point psychrometer. The method is suitable for describing the water retention behaviour along the main drying and wetting paths and for highlighting the hysteretic behaviours of retention curve. The systematic measurement of volume changes along the wetting and drying paths allowed for the computation of the degree of saturation and for the assessment of the shrinkage limit of each material.

A new high-pressure oedometric cell was introduced to analyse the transition from the over- to the normally consolidated state of shales. Attainment of a vertical effective stress in the range of $30-100 \mathrm{MPa}$ was needed to measure the yield vertical stress. Analysis of the settlement versus time curves yielded information on the consolidation parameters and the permeability at various stress levels and void ratios. 
Acknowledgments. The authors acknowledge the Swiss National Cooperative for the Disposal of Radioactive Waste (NAGRA) for supporting these research activities. The authors would like to acknowledge the research assistants, Donatella Manca and Paul Witteveen, for their help with the experimental work.

\section{References}

Cardoso, R., Romero, E., Lima, A., Ferrari, A.: A comparative study of soil suction measurement using two different high-range psychrometers. In: Schanz, T. (ed.) 2nd Int. Conf. on Mech. of Unsat. Soils, Weimar, Germany, pp. 79-93. Springer, Berlin (2007)

Horseman, S.T., Harrington, J.F., Noy, D.J.: Swelling and osmotic flow in a potential host rock. Physics and Chemistry of the Earth, Parts A/B/C 32(1-7), 408-420 (2007)

Leong, E.-C., Tripathy, S., Rahardjo, H.: Total suction measurement of unsaturated soils with a device using the chilled-mirror dew point technique. Géotechnique 53(2), 173$182(2003)$

Mäder, U.: Recipe and preparation of a simplified artificial pore water for Opalinus Clay and Brown Dogger. NAGRA AN 11-159 (2011)

Manca, D., Ferrari, A., Laloui, L.: Analysis of 1D high-pressure consolidation tests considering time dependent loading (in prep., 2012)

Muñoz, J.J.: Thermo-hydro-mechanical analysis of soft rockapplication to a large scale heating test and large scale ventilation test. PhD dissertation, Universitat Politècnica de Catalunya, Spain (2007)

Pearson, F.J.: Opalinus Clay experimental water: A1 Type, Version 980318. PSI Internal report TM-44-98-07, Paul Scherrer Institut, Villigen PSI, Switzerland (1998)

Peron, H., Hueckel, T., Laloui, L.: An improved volume measurement for determining soil water retention curves. Geotechnical Testing Journal 30(1), 1-8 (2007)

Ramos Da Silva, M., Schroeder, C., Verbrugge, J.-C.: Unsaturated rock mechanics applied to a low porosity shale. Engineering Geology 97, 42-52 (2008)

Romero, E., Senger, R., Marschall, P.: Air Injection Laboratory Experiments on Opalinus Clay. Experimental techniques, Results and Analyses. In: 3rd EAGE Shale Workshop, Barcelona, January 23-25 (2012)

Salager, S., Ferrari, A., Laloui, L.: New experimental tools for the characterization of highly overconsolidated clayey materials in unsaturated conditions. In: Laloui, L. (ed.) Mechanics of Unsaturated Geomaterials, pp. 113-126. John Wiley \& Sons (2010)

Thomson, W.: On the equilibrium of vapour at a curved surface of liquid. Phil. Mag. 42, 448-452 (1871)

Valès, F., Nguyen Minh, D., Gharbi, H., Rejeb, A.: Experimental study of the influence of the degree of saturation on physical and mechanical properties in Tournemire shale (France). Applied Clay Science 26(1-4), 197-207 (2004)

van Genuchten, M.T.: A closed-form equation for predicting the hydraulic conductivity of unsaturated soils. Soil Sci. Soc. Am. J. 44, 892-898 (1980)

Zhang, C.-L., Rothfuchs, T., Su, K., Hoteit, N.: Experimental study of the thermohydromechanical behaviour of indurated clays. Physics and Chemistry of the Earth 32(8-14), 957-965 (2007) 